\title{
A Soft Target Threat and Risk Methodology Application
}

\author{
N.Cajkova \\ Tomas Bata University in Zlin \\ Czech Republic
}

\begin{abstract}
This article is focused on a Soft Target Risk application and Threat Analysis Methodology at the Faculty of Applied Informatics in Zlin. The terrorist attacks are one of the biggest security problems in the modern world.

Attacks are often against Soft Targets which are places, that are typical of a high concentration of people and in the same time a low level of security.

As a Soft Target we can imagine shopping centers, airport terminals, sporting arenas, airport terminals, public meetings, schools, cinemas, religious events, etc. This paper focuses of the security analysis of the Faculty of Applied Informatics (Soft Target) and its preventive safety measures.
\end{abstract}

Keywords-Faculty of Applied Informatics, Method, Soft Target, Terrorism.

\section{INTRODUCTION}

$\mathrm{T}$ ERRORISM. A word people hear about every day. A word that - along with populism, changes the election results. A word that makes people feel, but that feeling is mostly fear. It is not known how long people have been dealing with terrorist attacks.

However, for the first time this term was used during the French Revolution [1]. Despite the fact that the word "terrorism" has remained the same since the 18th Century, the techniques of individual terrorist attacks have undergone dramatic innovations practically every day since then.

Terrorism entered into widespread public awareness after the attack in the United States of America, when thousands of innocent citizens lost their lives on September 11, 2001 other innocents suffered physical and - above all, psychological damage [2].
From this imaginary milestone, we have encountered and heard about terrorist attacks around the world every year. Most of these attacks are sophisticated, planned well-ahead and are committed for a variety of reasons.

It is very difficult to detect these attacks in time and to prevent them, especially if they are directed against defenceless citizens, or demolishing infrastructure, or creating chaos and fear.

It is therefore in the best interests and efforts of most of today's states to improve preventive security measures in order to defend against a possible terrorist attack.

\section{FACULTY OF APPLIED INFORMATICS}

The reference building is located north of the city centre of Zlín, in the part called Jižní Svahy (Southern Slopes). The Jižní Svahy location is characterised by the high number of apartment buildings. Almost a quarter of the total population of Zlín (76 000 inhabitants) lives here. This area is not a significant commercial or industrial zone [3], [4].

The Faculty of Applied Informatics is a complex that consists of individual pavilions. The roof, ceiling and loadbearing structure of the building are made of non-combustible material. Each pavilion has a different number of floors, but the individual pavilions are interconnected. The highest block of the building has 8 floors [5].

Accessibility to each floor is possible by stairs or one of the two elevators. The reference object is open daily from 06:00 to 22:00. The largest accumulation of people in the building is between 09:00 and 15:00, when most lectures take place, seminars and scientific activities. The building is constantly guarded by physical security throughout the day. 


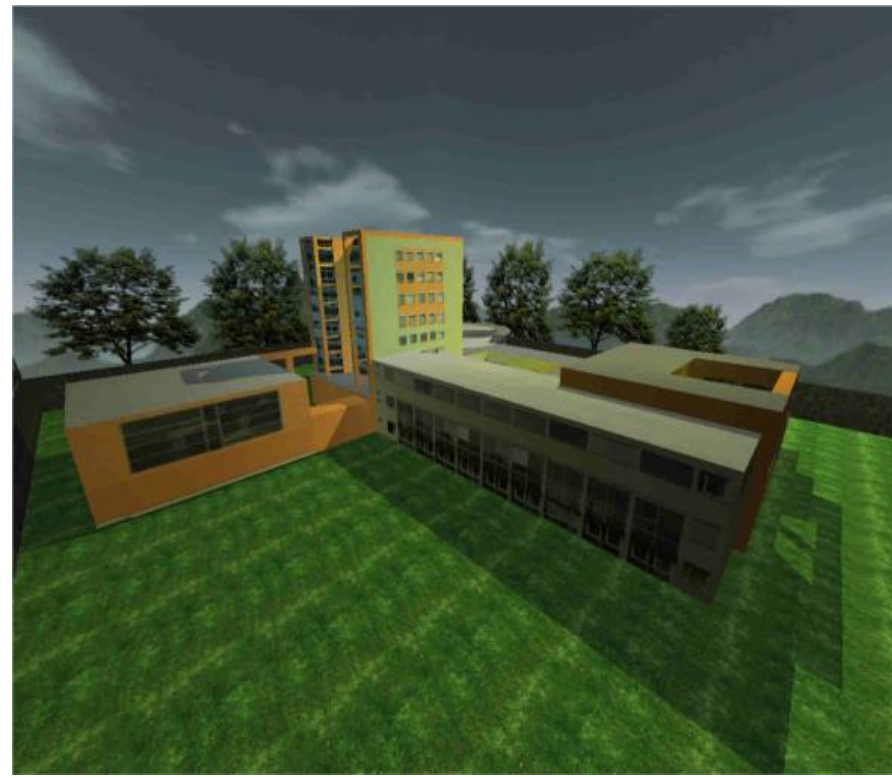

Fig. 1 Faculty of Applied Informatics [6]

\section{A. Attendance}

Attendance in the reference building varies significantly depending on the schedule of the academic year. The graph below shows the estimated average attendance of students and teachers at the FAI in the summer semester on weekdays, within the compulsory activities recorded by STAG information systems. The data are based on the database of the information system for the period 4 February 2019 - 10 May 2019.

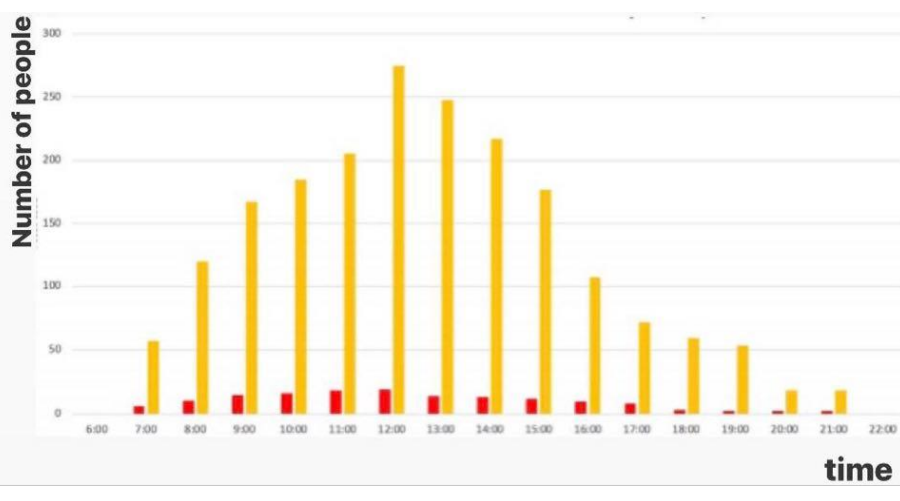

Fig. 2 Attendance at Faculty of Applied informatics through the day [7]

\section{B. Security precautions}

As already mentioned, the physical security system is handled by physical security, which is hired by the security company SG'3. The security guards continuous supervision of the building, which is assisted by an integrated control center with camera system. The camera system supervising the surroundings of the object. Security guards must record visitors, providing information, sorting mails, recording faults, etc.

Physical security has a two-shift operation, which also weighs the differences of individual shifts. The reference building is open until $10 \mathrm{pm}$, but supervision of the building and its surroundings continues even after the building is closed.

The technical protection system is implemented using PZTS, EPS and CCTV and ACS elements. PIR detectors are located in each lecture and seminar room. These are all floors to the 3rd floor (inclusive) and generally there are detectors in each room that has windows.

Then there is one long range PIR detector on each floor. Cameras are located at the entrance door and the entrance door is equipped with magnetic contacts connected to the EPS. There are also optical smoke detectors, sirens and emergency buttons in the classrooms.

As for the access control system, it is performed in the form of card readers at selected locations inside the building and the so-called key service with the participation of physical security, which has in the description of the work of issuing keys to authorized people.

\section{METHODS}

Nowadays, we have many methods for analysing reference objects. Each method is different and many of them also use software tools. Individual methodologies are based on physical models that differ in complexity and segmentation. The accuracy and reliability of the outputs then differ depending on their complexity. In the majority of cases, these were created in order to identify risks for specific companies or institutions.

Individual methods can be divided according to different points-of-view, one of which is the division into induction and deduction. Induction methods allow one to predict equipment failure in a coherent the operating system.

This analysis will point out the possible effects that can cause failures, while assessing the consequences of such failures, and then take appropriate measures; while deduction methods analyse accidents and investigate the context from which they arose. Methodologies can also be divided into qualitative and quantitative. However, the biggest difference and the criterion for choice in corporations is usually time and cost [7], [8].

\section{SOFT TARGET RISK AND THREAT ANALYS}

In Soft Target Risk Application and Threat Analysis Methodology must be determine location and timing of potential attack. The location of the reference object is divided into outdoor and close surroundings. The time is divided into section when the building is open and lectures can be held (06:00 - 22:00) and other section when the building is locked and guarded (22:00 - 06:00) [9].

It is also necessary to determine probability that the attack will occur in individual time sections. The evaluation is given by availability, complexity and attractiveness of the reference object.

The risk is examined from different sub-categories specific to the reference object. In the case of Faculty of applied Informatics (FAI) with a focus on terrorist attack, the main subcategory is impact on lives and on society. Each subcategory is rated separately on scale from 1 to 7 by characteristics from low to high level of risk [10], [11]. 


\begin{tabular}{|c|c|c|c|c|c|}
\hline \multirow[b]{2}{*}{ Hazard } & \multirow[b]{2}{*}{ Location } & \multirow[b]{2}{*}{ Timing } & \multicolumn{3}{|c|}{ Separation energies } \\
\hline & & & Total Threat & $\begin{array}{l}\text { Total } \\
\text { Risk }\end{array}$ & $\begin{array}{l}\text { Overall } \\
\text { Hazard }\end{array}$ \\
\hline $\begin{array}{l}\text { Attack with a cold } \\
\text { weapon }\end{array}$ & In the FAI & During lectures & 20 & 9 & 180 \\
\hline $\begin{array}{l}\text { Attack with a cold } \\
\text { weapon }\end{array}$ & In front of the FAI & During lectures & 17 & 7 & 119 \\
\hline $\begin{array}{l}\text { Attack with a cold } \\
\text { weapon }\end{array}$ & In front of the FAI & Off schedule & $\mathrm{X}$ & $\mathrm{X}$ & $\mathrm{X}$ \\
\hline Gun attack & In the FAI & During lectures & 18 & 10 & 180 \\
\hline Gun attack & In front of the FAI & During lectures & 16 & 8 & 128 \\
\hline Gun attack & In front of the FAI & Off schedule & $\mathrm{X}$ & $\mathrm{X}$ & $\mathrm{X}$ \\
\hline Arson & In the FAI & During lectures & 19 & 12 & 228 \\
\hline Arson & In front of the FAI & During lectures & 17 & 12 & 204 \\
\hline Arson & In front of the FAI & Off schedule & 21 & 14 & 294 \\
\hline $\begin{array}{l}\text { Hostage and barricade } \\
\text { situation }\end{array}$ & In the FAI & During lectures & 15 & 8 & 120 \\
\hline $\begin{array}{l}\text { Hostage and barricade } \\
\text { situation }\end{array}$ & In front of the FAI & During lectures & 14 & 7 & 98 \\
\hline $\begin{array}{l}\text { Hostage and barricade } \\
\text { situation }\end{array}$ & In front of the FAI & Off schedule & $X$ & $\mathrm{X}$ & $\mathrm{X}$ \\
\hline \multicolumn{6}{|l|}{ Bomb delivered by mail } \\
\hline Bomb delivered by mail & 1 In the FAI & During lectures & 12 & 10 & 120 \\
\hline Bomb delivered by mail & 1 In front of the FAI & During lectures & $\mathrm{X}$ & $\mathrm{X}$ & $\mathrm{X}$ \\
\hline Suicide bombing attack & In front of the FAI & Off schedule & $\mathrm{X}$ & $\mathrm{X}$ & $\mathrm{X}$ \\
\hline Suicide bombing attack & In the FAI & During lectures & 10 & 13 & 130 \\
\hline Suicide bombing attack & In front of the FAI & During lectures & 8 & 12 & 96 \\
\hline
\end{tabular}

Fig. 3 The overall level of threat depending on the location and timing of the attack [10] 


\begin{tabular}{ll}
\hline$\underline{\text { Risks }}$ & Characteristics \\
\hline $\mathbf{1 .}$ & Shock \\
$\mathbf{2 .}$ & Slight Injury \\
$\mathbf{3 .}$ & Serious Injury \\
$\mathbf{4 .}$ & Attack on individuals \\
& Impact on the lives of people in the immediate \\
$\mathbf{5 .}$ & vicinity \\
6. & Imminent threat to the lives of the group present \\
7. & Imminent threat to the lives of all present
\end{tabular}

Fig. 4 Life Impact Table [10]

\section{ANALYSIS RESULTS}

After identifying the individual subcategories and calculating the overall hazard by the formula: Hazard = Risk $\mathrm{x}$ Threat, the resulting data is subjected to location and time factor of the attack. Figure 5 depicts that the location of the attack in front of or in the object is almost identical.

This is mainly due to the factor of the high concentration of persons before the main entrance into the building - especially in regular intervals between classes, pauses and the leisure assets of the reference object. On the other hand, Figure 6 shows the localisation of thread based on the daily attack time - and therefore we can see that the students and academic staff of the faculty are particularly at risk when lessons are taking place.

\section{In the building In front of the building}

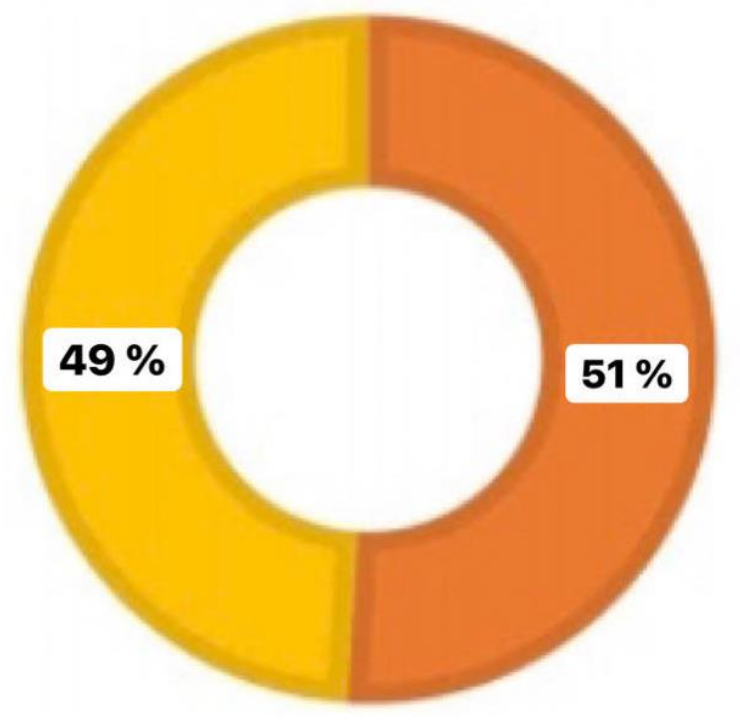

Fig. 5 Localisation of Threat [11]

\section{During lectures}

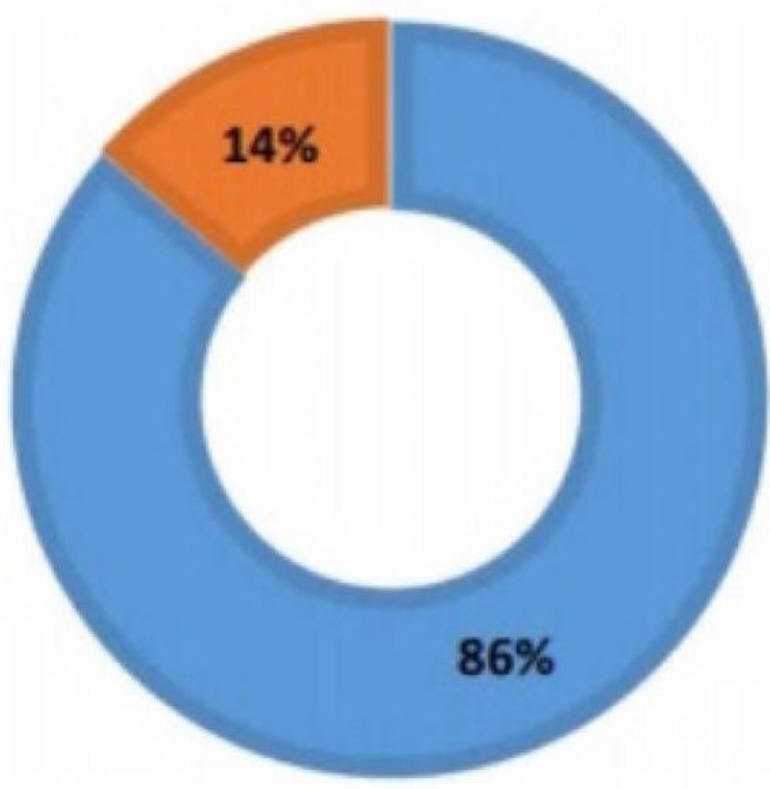

Fig. 6 Thereat Level Depending on Time of Day [11]

\section{RESULTS AND DISCUSSION}

The Soft Target Risk Application and Threat Analysis Methodology deals with attacks in terms of accessibility, complexity, attractiveness and their consequent impact on community and lives. After determining the likelihood of a risk and threat, their multiplication shows the total rate of hazard. This hazard is either acceptable or unacceptable depending on its value. The unacceptable risks were evaluated by aspects of location and time of the potential attack.

Analysing Soft Target Risk Application and Threat Methodology is very beneficial. Compared to other methodologies that do not include these aspects, this one has a clear outcome. However, it is not one of the fastest methods. The result of an exact determination of hour and localization of the time and place can also save money. Of course, the best option is to combine multiple methods to increase the probability of the terrorist attack.

Based on the results of the methodology, it is easier to see potential threats and specific places in the reference object, which should be focused on when improving the security of the object.

\section{CONCLUSION}

Terrorism is nowadays world issue and it is very difficult to detect and prevent a terrorist attack. However, due to methodologies and preventive safety measures, the possibility of better preparedness or even the prevention of a terrorist attack is possible.

This article focuses on a specific Soft Target and the application of methodology. The result of the methodology shows the weak points of the reference object. The future work would be to focus on these weak points and propose new security measures. 


\section{References}

[1] OŠŤÁDALOVÁ, Š. Terrorism in history and international law. Legal space [online]. Praha: Praha, 2003 [cit. 2020-01-29]. Retrieved from: https://www.pravniprostor.cz/clanky/mezinarodni-aevropske-pravo/terorismus-v-dejinach-a-mezinarodnimpravu

[2] 11th September 2001. Ten years later. Praha: Cepin, 2011. ISBN 978-80-87460-06-1.

[3] Thomas Bata University in Zlin Faculty of Applied Informatics[online]. Zlín: UTB, 2019 [cit. 2020-01-29]. Retrieved from: www.fai.utb.cz

[4] Official website of the statutory city of Zlín [online]. Zlín: Zlín, 2019 [cit. 2020-01-29]. Retrieved from: www.zlin.eu

[5] Interactive map of the building: U5 [online]. Zlín: UTB, 2019 [cit. 2020-01-29]. Retrieved from: http://www.imb.fai.utb.cz/

[6] STALMACH, J. Faculty of Applied Informatics in Zlin. In: Jan Stalmach: homepage [online]. Zlín: download.html, 2007, 2007 [cit. 2020-01-29]. Retrieved from: https://www.stalmach.name/data/utb2007.jpg

[7] ŠEFČÍK, V. Risk Analysis. Zlín: Thomas Bata University, 2009, 98, s. ISBN 978-80-7318-696-8.

[8] BUZALKA, J. Security Risk Theory. Bratislava: Police Force Academy, 2012, 167 s. ISBN 978-80-8054-547-5.

[9] Timetable of teaching and events connected with teaching at FAI TBU in Zlín for the academic year $2019 / 2020$. Zlín, 2019. Retrieved from: https://fai.utb.cz/ofakulte/uredni-deska/harmonogram-akademickeho-roku/

[10] KALVACH, Z. Methodology for threat and risk analysis for soft targets. 1. Praha, 2017.

[11] ČAJKOVÁ, N. Possibilities of securing teachers and students against terrorist attacks in the U5 building at TBU in Zlín. Zlín, 2019. Thesis. Univerzita Tomáše Bati. Supervisor doc. Ing. Libor Pekař. Ph.D.

\section{Creative Commons Attribution License 4.0 (Attribution 4.0 International, CC BY 4.0)}

This article is published under the terms of the Creative Commons Attribution License 4.0 https://creativecommons.org/licenses/by/4.0/deed.en_US 